Portland State University

PDXScholar

\title{
The relationship of the perception of choice and positive behavior change in adolescent residential treatment with future success in the community
}

Rita Harding McClellan

Portland State University

Follow this and additional works at: https://pdxscholar.library.pdx.edu/open_access_etds

Part of the Psychoanalysis and Psychotherapy Commons, and the Psychology Commons Let us know how access to this document benefits you.

\section{Recommended Citation}

McClellan, Rita Harding, "The relationship of the perception of choice and positive behavior change in adolescent residential treatment with future success in the community" (1988). Dissertations and Theses. Paper 3811.

https://doi.org/10.15760/etd.5695

This Thesis is brought to you for free and open access. It has been accepted for inclusion in Dissertations and Theses by an authorized administrator of PDXScholar. Please contact us if we can make this document more accessible: pdxscholar@pdx.edu. 
AN ABStRACT OF THE THESIS OF Rita Harding McClellan for the Master of Science in Psychology presented January 7 , 1988

Title: The Relationship of the Perception of Choice and Positive Behavior Change in Adolescent Residential Treatment with Future Success in the Community.

APRROVED BY MEMBERS OF THE THESIS COMMITTEE:
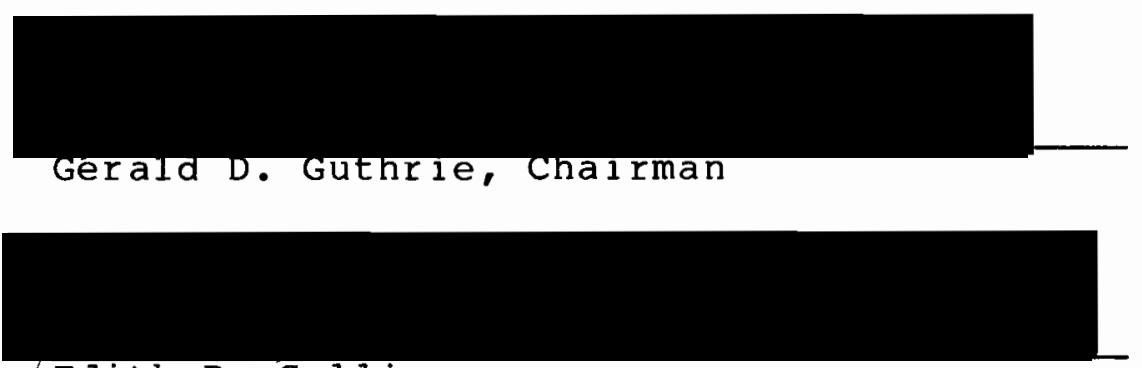

Edith B. Sullivan

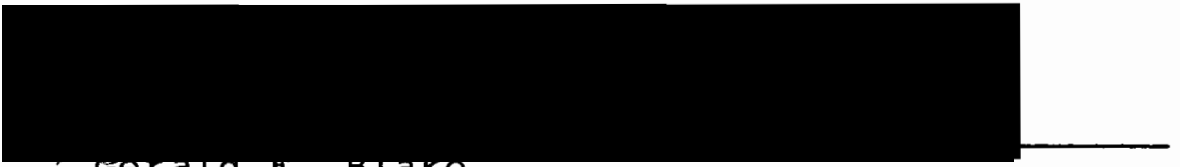

Gerara i

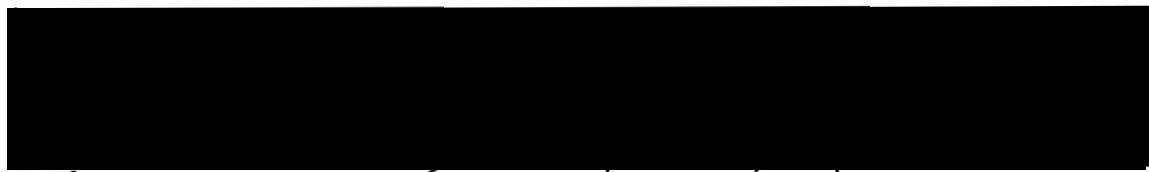

Thomas Young

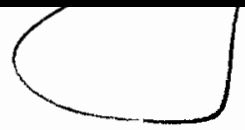

The purpose of this study was to explore the relationship of clients' perception of choice in treatment planning and the clients' positive behavior changes made within the treatment setting, with the clients' successful return to the community after release from the residential treatment setting 
The 32 subjects in this study were male adolescents who, within an 18-month period prior to the study, had been released from a residential treatment center and had returned home to the community to live. All of the subjects had been court-ordered into the residential treatment center, where they lived for a period of 3 to 6 months, due to having at least one adjudicated law violation.

The subjects were located in the community where they completed two questionnaires. One questionnaire contained questions regarding the amount of choice the subject perceived himself to have had in developing and working towards his treatment goals within the four program components (employment, education, family counseling, and group living) at the treatment center. The second questionnaire contained questions focusing on the subject's status in the areas of employment, education, and living situation since his return to the community. This data was used in assessing whether or not the subject had made a successful return to the community.

In addition to the choice questionnaire and the community status questionnaire given to the former clients, staff members from the residential treatment center also completed a questionnaire. One staff person from the employment, education, family counseling, and group living program components who had previously worked with the 
subject during his residential stay gave a rating as to the amount of positive behavior change they perceived the client to have made while he participated in their specific program component.

A discriminant analysis was performed on the data to assess whether or not there was any relationship between client choice in treatment and their success in the community. The discriminant analysis produced results indicating that there was a significant relationship between client choice in family counseling and client success in the community. $\underline{F}(2,29)=3.321, \underline{p}<.05$. No significant relationship was found between client choice in education, employment, and group living and client success in the community. When using the client's perception of choice in treatment as a predictor of client success in the community, 17 out of the 32 cases were accurately predicted.

A discriminant analysis was also used to assess whether or not there was any relationship between the staffs' ratings of client behavior change in residence and client success in the community. The multivariate test for the staffs' ratings of client residential behavior change and its overall predictive value of client success in the community was significant, $\underline{E}(12,46)=2.258$, $\underline{p}<.05$. Staffs' ratings of client residential behavior change was accurately predictive of the client's actual community success in 22 out of the 32 cases. 
ThE RELATIONSHiP OF ThE PERCEPTION OF CHOICE AND POSITIVE BEHAVIOR CHANGE IN ADOLESCENT RESIDENTIAL TREATMENT WITH FUTURE SUCCESS IN THE COMMUNITY

$$
\text { by }
$$

RITA HARDING MCCLELLAN

A thesis submitted in partial fulfillment of the requirements for the degree of

\author{
MASTER OF SCIENCE \\ in \\ PSYCHOLOGY
}

Portland State University

1988 
TO THE OFFICE OF GRADUATE STUDIES AND RESEARCH:

The members of the Committee approve the thesis of Rita Harding McClellan presented January 7, 1988.
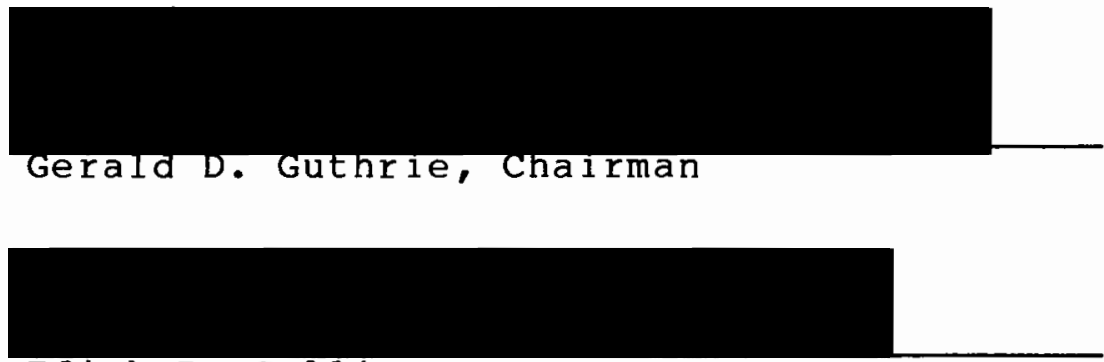

Edith B. Sullivan

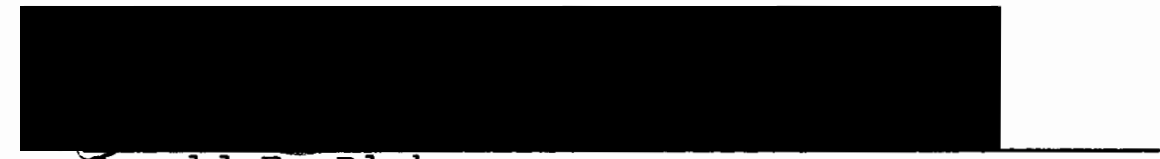

Gerald F. Blake

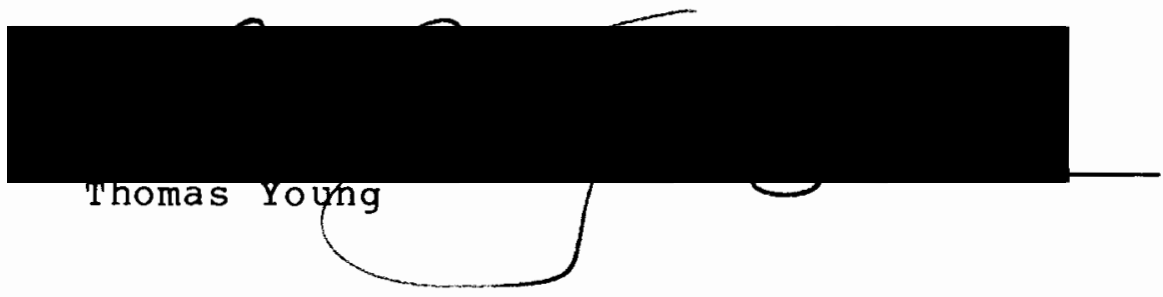

APPROVED:

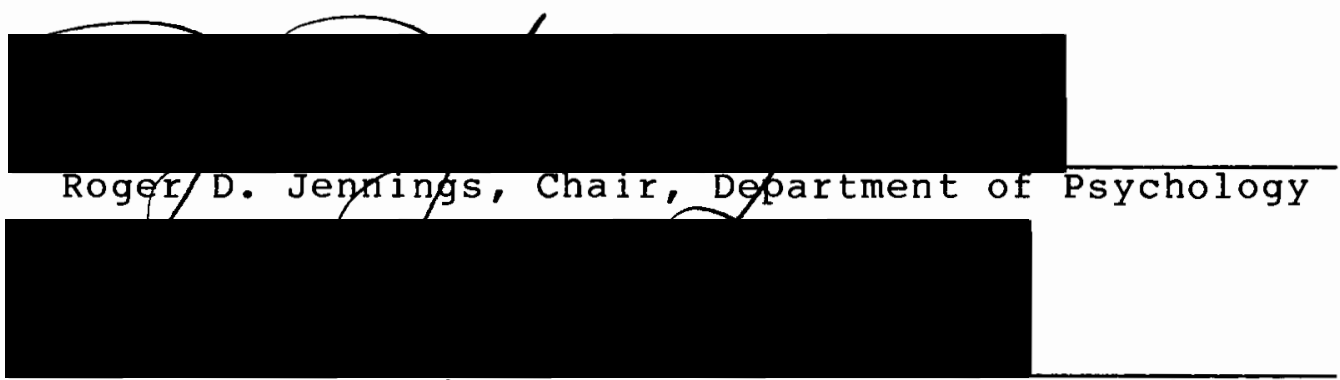

Bernard Ross, Vice Provost for Graduate studies 


\section{ACKNOWLEDGMENTS}

I would like to thank my committee members, Dr. Edith Sullivan and Dr. Gerald Blake, for their patience, their helpful comments and feedback, and for their ongoing support in making this research project possible. My greatest thanks goes to my advisor, Dr. Gerald Guthrie. This research study was a long and sometimes frustrating project, but Dr. Guthrie believed in me and this study. Without his continuing support and encouragement, it would never have been completed. During those times when I felt like giving up, Dr. Guthrie's sense of humor and words of advice always helped me to keep on going.

A very special thanks goes to Dr. Dean Frost for all of his help in the statistical area of this study. Statistics have never been a strong point of mine, but Dr. Frost, despite how unintelligent I must have seemed to him at times, was patient and supportive. He helped to make this part of the study exciting, comprehendible, and a little less frightening.

My parents, Darrell and Phyllis Harding, are the greatest people on earth. Even though they have never really understood any aspect of this research project, they have been there every step of the way with their 
love, encouragement, and tireless devotion. Theirs is the greatest $g$ ift of all, belief in myself that $I$ can do anything that I set my mind to do.

I could never escape this lengthy acknowledgment page without giving a very special recognition to the most supportive and confidence-building force in my life, my husband steve. I think there were times that I drove him crazy with this never ending thesis project, but he never complained once. Throughout all of the hours that this project robbed us of times we could have spent together, throughout all of the uncooked dinners due to long library and computer nights, and throughout all of the tears and frustrations, he stood firmly beside me with total love, commitment, and faith in me. I admire this very special man, greatly.

Finally, to the rest of my family and friends, thank you for never having to utter those horrifying words again, "Aren't you finished with that thesis yet?" 
TABLE OF CONTENTS

PAGE

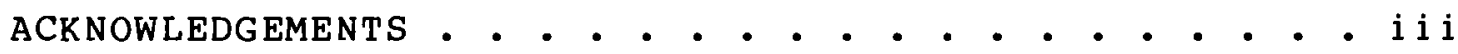
LIST OF TABLES •

CHAPTER

I INTRODUCTION $\quad \cdot \quad \cdot \quad \cdot \quad \cdot \quad \cdot \quad \cdot \quad \cdot \quad \cdot \quad \cdot \quad \cdot \quad 1$

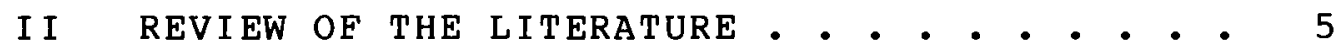
I I METHOD:

Subjects • • • • • • • • • • • • • 12

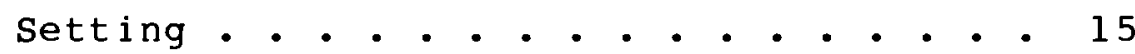

Family Counseling . . . . . . . . 16

Education . . . . . . . . . . . . 16

Youth Employment Program . . . . 17

Group Living •. . . . . . . . . . 18

Procedure • . . . . . . . . . . • . 19

IV RESULTS • • • • • • • • • • • • • • • 21

$\mathrm{V}$ DISCUSSION . . . . . . . . . . . . 30

REFERENCES • • • • • • • • • • • • • • • • • • • • • APPENDICES :

APPENDIX A • • • . . . . . . . . . . 42

Informed Consent

Authorization of Information Release 
PAGE

APPENDIX B - Choice Questionnaire •. . . . 44 APPENDIX C - Subject Interview Questions • 46 APPENDIX D - Staff Questionnaire • • . . 48 APPENDIX E - Pearson Correlation Results . 56 
the residents in these facilities are drug and alcohol counseling, family therapy, individual counseling, employment programs, school programs, and recreation programs. All of the programs have one common goal, despite what services they offer. Their goal is to provide treatment to the adolescent offenders so that they may make the necessary changes in their lives to return to the community and lead productive and successful lives.

I have worked in three residential treatment centers in the Portland area within the past seven years. I have worked in secure and nonsecure facilities. I have worked in programs for only females, in programs for only males, and in programs where both males and females lived. Within these agencies I had experience as a youth care worker and as a family counselor. I always enjoyed my work experiences in these facilities, and I usually felt that the program had helped the adolescent client in some way; but there was always one aspect that I continually felt frustrated about, despite what program I was working in. Within these three residential programs, the adolescent clients were not given much decision-making responsibility in their individual treatment programs. It frequently seemed to me that the clients were not asked what specific areas they thought needed to change in order for them to be more successful in the community. The counselors who worked with these youth operated on the 
assumption that they were the professionals who had all of the answers that would change these clients. More often than not, treatment plans were developed for the clients without any input from them. The net effect of this, from what I observed, was that the clients would make the minimal behavior changes required of them by the professionals that would allow them to be released and return home to 1 ive. In my job as a family counselor providing support services to the family after the youth returned home, it became evident, in terms of the high recidivism rate, that these clients were not assimilating the behavior changes made in residence to the community. Upon asking the clients the reasons for this, many stated that with no real investment they made a few of the behavioral changes expected of them so they could return home as soon as possible. A lot of these adolescents did not agree with the treatment goals developed for them by the professionals, but they "played the game" so they would look successful in the eyes of the professionals.

Because of these personal experiences, I decided to pursue these theories and design the present research study to explore the perception of choice and behavior change of the juvenile offender in treatment with success in the community after his return home. It seems that today, in our present society, adolescence is a frustrating time period for youth due to the lack of rights and 
the lack of decision-making opportunities given to them. At a time when adolescents need to believe in their own value and self-worth, they are forced to be passive and dependent. A common attitude in adults today is that they know what is best for the youth. This line of thought robs the adolescent of the opportunity to make his own decisions and to experience the consequences of his choices. By not allowing the adolescent these experiences, we may not be helping him to develop a sense of responsibility and personal values. 
CHAPTER I I

REVIEW OF THE LITERATURE

The rate of serious crimes committed by juveniles has increased alarmingly during the past decade. According to the U.S. Department of Commerce, out of the 2,151 serious crime arrests reported in the United states in 1983, 30.4\% were committed by those under the age of 18 . This presents two significant problems for the juvenile justice system: that of protecting the community from the juvenile offender and that of providing treatment rehabilitation for the offender. At present, there exist many different approaches to these problems. There are group homes, foster homes, residential treatment centers, mental hospitals, proctor homes, state training schools, community counseling agencies, and drug rehabilitation centers, just to name a few of the many programs available to the juvenile offender. One question that this raises is: How effective are these programs in successfully rehabilitating these youth? Secondly, of those programs that are effective, what factors are common among them that are instrumental in promoting these positive behavior changes in the offender?

In a 1976 report performed for the National 
Institute of Juvenile Justice and Delinquency Prevention by Dale Mann, he reported that one common characteristic he found among successful treatment programs serving the juvenile offender was that of client participation. Those programs that allowed the client more involvement and choice in the treatment process experienced more thorough and lasting functional change in their clients than those programs which did not allow for client involvement.

This concept of allowing people choice in their decision making, and the positive effects this has on performance, has gathered a great amount of research support (Baum \& Singer, 1980; Brehm, 1966; DeCharms, 1968; Langer, 1975; Lefcourt, 1976; and Rotter, 1966). There have been some research studies that specifically address the effects of choice on therapeutic behavior changes in the client.

In 1976, Langer and Rodin performed a research project in a nursing home where they attempted to assess the effects that increased personal choice had on the patients. The subjects in the experimental group were given communication emphasizing that they had choice about how their rooms were furnished and arranged, how they wanted to spend their free time, and that if they had any complaints about the program, then they were to share these with the staff. The comparison group received information emphasizing that the staff were in charge of 
the program and that they made most of the decisions. Of the patients in the comparison group, $71 \%$ became more debilitated within the three-week period as measured by ratings from themselves and staff and from behavioral measures of attendance in nursing home activities. In contrast, $93 \%$ of the experimental group members showed an overall improvement as measured by the same criteria. The authors concluded that allowing patients choice and decision-making in the program produced an improvement in functioning.

The effects of offering clients a choice in therapist was researched by Ersner-Hershfield, Abramowitz, and Baren in 1979. In this study clients at a community health center were given the opportunity to choose their therapist on the basis of style. It was hypothesized that clients who could choose their therapist would more often come to the first interview than those who had no choice in the therapist they received. They found that of those who experienced choice, $71 \%$ showed up for the initial session as compared to $45 \%$ of the no-choice group of subjects. In addition, the show rate for the choice group was also significantly higher than that of clients scheduled for initial interviews during the month preceding the study. The authors interpreted the results as suggesting that the opportunity to have decision-making ability during the initial clinical contact increased the clients' 
investment in following through with their initiative.

In Robert M. Gordon's study in 1976 at Temple University, he predicted that subjects who were given the responsibility to decide between two treatments would view the treatment as more effective than those subjects who were not given the opportunity of choice. Volunteer subjects were assigned to either a choice or a no-choice condition. The subjects in the choice group were asked to pick a treatment tape they would prefer to receive. The no-choice subjects were denied this option to choose. In reality, all of the subjects viewed the same relaxation tape. The results were significant, in that those who perceived that they had choice valued the treatment more and reported the treatment to be significantly more effective than those who had not been told that they had a choice in therapy.

In 1973 Devine and Fernald found that subjects' fear reduction of snakes was more significantly reduced when they were placed in a condition where the therapy was of preferred choice than when the subjects were in a nonpreferred condition or in the control group. The subjects viewed a videotape of four therapists who described their therapy techniques for treating the fear of snakes, and the participants were then placed in a preferred or a nonpreferred therapy group. A control group who had not viewed the tapes or indicated a therapy preference were 
randomly assigned to the various therapies. The results supported the notion that by allowing clients more choice in the therapeutic situation, more positive behavior changes are the outcome.

Janzen and Love's study in 1977 also supports the concept of client choice in treatment. Their study, performed in a group home of female clients, is somewhat unreliable because of the lack of statistical testing, although it still lends some support for this concept of choice. The treatment program in a group home was ineffective in producing behavior change. Four changes were implemented in the program: (1) the child was not labeled during the treatment; (2) the child was given the choice about whether or not her treatment plan was suitable; (3) the child was given the decision-making power in identifying her problem areas; (4) the child was involved in assessing treatment effectiveness. The houseparents and residents were interviewed after these changes had taken effect, and it was found that the clients' behavior improved and that the interpersonal relationships between the staff and the girls had improved. The authors noted that

- . not only did these girls have input regarding behaviors needing change, but they also assisted in determining the positive and negative consequences. It was no longer an external agent demanding change or imposing punishment and rewards, but rather the girls' themselves. 
Bastien and Adelman, 1984, performed a study in which they measured the effects of choice within a residential treatment setting for adolescent offenders. They hypothesized that positive responses to social rehabilitation interventions are associated more with noncompulsory than with court-referred placement, and that the degree of compulsory referral is significantly related to the degree of perceived choice. Their results indicated that there was no significant relationship between the degree of compulsory referral and the degree of perceived choice. The relationship between treatment progress and compulsory referral was also not significant. What they did find was that it was not important whether clients were court-mandated or noncompulsory, but whether or not they had experienced informed consent procedures. Informed consent procedures included preplacement visits, decision-making input about which program he would enter, and information and assurances that the placement decision would be reconsidered if the resident raised serious objections after a trial period.

The relationship between informed consent procedures and the perception of choice was significant, meaning that despite being compulsory or noncompulsory, if a client had experienced informed consent procedures, he perceived himself as having more choice than if he had not experienced these procedures. The relationship between perception of 
choice and treatment progress was also significant in that those who perceived themselves to have choice did better in treatment than those who did not see themselves as having choice. Based on the findings in this study, informed consent procedures may be an important factor that should be considered in residential treatment facilities serving the population of young offenders. Adolescents, who feel like passive objects manipulated by authority figures in society, may experience a sense of control over their lives by being given choices about their treatment.

The present study explored the relationship between choice in the treatment process and the effects on successful behavior change within the community after being released from a treatment center. The relationship between behavior change in the therapeutic environment and success in the community was also explored in this study. It was hypothesized that former adolescent residents of a residential youth care center who perceived themselves as having had choice within their treatment programs made more lasting and functional behavior changes upon their return to the community than those residents who did not perceive themselves as having had choice in their treatment. It was also hypothesized that those clients who made more positive behavior changes while in residential treatment would continue to engage in the successful 
behavior changes more often after their return to the community than those clients who did not make as many behavior changes while in the treatment center. 


\section{CHAPTER I I I}

METHOD

\section{Subjects}

The participants in this study were white males between the ages of 15 and 19 years who had been released from a residential treatment center within the last 18 months. These subjects were chosen for the study because of the researcher's affiliation with the residential center, thereby allowing accessibility to the clients. Due to difficulty in locating and contacting the subjects, and due to the limited number of clients released from treatment during an 18-month time period, a sample size of 32 subjects participated in the study.

A control group was not included in this study due to ethical problems in withholding treatment from clients in the residential setting. Clients who had been released from the program were chosen for this study instead of those who are presently in residential treatment for various reasons. The first reason is that a residential setting is a more controlled and restrictive environment than that of a natural living environment in the community. Due to these restrictions, a subject in residence may have a distorted perception of his degree of choice. 
Another reason is that a subject may not feel that he has the freedom to give honest information about the program because of his fear that this information may influence his present and future progress and status within the program. Lastly, it is of specific interest to this study to measure the success of the subjects after their return to the community. Since it is assumed that the residential setting is a more controlled environment than a community living situation, it seems likely that clients would make positive behavior changes more easily while in residence than in the community where there are more obstacles and adversities. It could be of great value to the clinician to measure how much of these behavior changes actually generalize to a less restrictive environment in the community.

There are some characteristics common to all of the subjects due to the factors that are inherent in the present residential youth care center. All of the residents are court-mandated into placement due to having been adjudicated for at least one law violation other than a status offense. Each subject, while in residence, was under the custodial supervision of Children Services Division, and each was on formal juvenile court probation. The residential center is a short-term treatment facility where clients remain from approximately 3 to 6 months. The subjects in the study have been released from 
the residential center and have returned to the community to live with their natural family, their foster family, in a relative's home, or to an independent living situation such as an apartment or a room and board arrangement. None of the subjects had entered another residential program directly after their release from the residential program in this study.

Setting

The nonsecure youth care center serves a population of 20 adolescent males and is located in a rural setting in oregon. The name of the residential center will not be used in this study in an effort to assure anonymity of the clients in this study. During the referral/intake process, the client is given a tour of the program and an explanation of the services offered. In a personal interview the client, his family, and the intake worker identify the goals of treatment. All parties must agree to these goals and must sign a contract before the boy will be accepted into placement. A service plan is then written, reflecting these identified treatment goals within each of the program components: family counseling; education; employment; and group living. This service plan is used throughout his residential placement to help monitor the progress of treatment. After entering residence, the following described services are provided for the client. 
Family Counseling

A family counselor is assigned to a resident and his family while he is in placement. Some examples of the choices that the resident is given while in family counseling are: the times and dates of counseling sessions; the specific family problem areas to be discussed; where he will live after his residential stay; the times and dates of home visits; the rules to be followed when at home with his family; and any consequences to be administered when the resident does not follow the rules. The counseling approach is based on a family systems model where conflict mediation is used as an intervention in conjunction with teaching the family new skills in problem solving, parenting, and communication. The resident has scheduled visits at home so that he and his family can practice these newly-acquired skills.

Education

There is a year-round school program at the residential center which is staffed by a teacher and an aide. The residents have a choice of either gaining transferable credits towards a high school diploma or pursuing the completion of a General Education Diploma. They are also given a choice about which days they will spend in the classroom. The curriculum offered includes general studies in the areas of mathematics, reading, social studies, English, and science, with approximately 10 students in the 
classroom each day. Throughout his placement, ongoing coordination and planning is done with the educational facility that the resident decides to return to after he leaves residence.

Youth Employment Program

There are three components to the youth employment program: the preemployment training class; the work cluster program; and the youth employment service program. The preemployment training class consists of field trips to businesses, films, guest speakers, learning appropriate job skills, interviewing techniques, resume writing, skills for a job search, and career exploration. Because of a standardized curriculum, the residents are not given a choice about which job skills they study when in this class. While learning these preemployment training skills, the resident is also given experience working at various jobs of his choice at the residential center while in the work cluster program. Once he has progressed through these steps and has demonstrated responsible and appropriate job skills, he is placed in a job of his choice within the community while he participates in the youth employment service program. The resident works with the employment counselor to determine which job placement in the community would be most appropriate for him, according to his specific interests, talents, and experience. Ongoing coordina- 
tion and support services are maintained with the community employer.

Group Living

Within the group living program, a resident is assigned to a staff member who is his youth care coordinator. The youth care coordinator and the resident work together to develop goals that focus on the individual behavior changes which the resident identifies he needs to work towards. Throughout his residential stay, the resident meets regularly with his coordinator to discuss the progress he is making on his treatment goals. The resident has the option to revise his goals at any time during his residential placement. The focus of the group living program is for the resident to learn appropriate hygiene and grooming skills, problem-solving skills to deal effectively with conflict, and skills in communication. In addition, the residents attend a support group for drug and alcohol issues; they attend daily problem-solving groups where residents are given the forum to discuss conflict areas within the program; and they also participate in leisure and recreational activities. The clients are expected to follow through with the rules of the program so that they may learn to live cooperatively with others. 
$\underline{\text { Procedure }}$

In the present study, the former residents were contacted by telephone and asked to participate in an evaluation of the services provided by the residential center with a specific emphasis on the area of choice and how he has adjusted in the community since his departure from residence. When the former client agreed to participate in the study, an appointment was scheduled to meet with him on an individual basis at his home in the community.

At the time of the interview, the subject was asked to complete a consent form (see Appendix A). There were two sets of questions asked of the subject. One set contained questions regarding the amount of choice the subject perceived himself to have had in developing and working towards his treatment goals within the employment, education, group 1 iving, and family counseling components of the residential youth care program. The subject read the questions on the questionnaire and then, on a scale of o to 4, rated the amount of choice he perceived himself to have had at the time. The o represented the least amount of choice, and the 4 represented the greatest amount of choice (see Appendix B).

The second set of questions focused on his status in the areas of employment, education, and living situation since his return to the community. These questions were 
used to assess a successful return to the community and were completed within a structured interview format (see Appendix C)

In addition to the questionnaire and interview data obtained from the former clients, information was also collected from the staff members of the residential center. A staff person from each of the program components who had worked with the subject during his residence was asked to give a rating on a specifically devised scale/questionnaire, with responses ranging from 0 to 4 , as to the amount of behavior change they perceived the client to have made while he participated in their specific program component (see Appendix D). 
CHAPTER IV

RESULTS

A factor analysis (i.e., a principal components analysis with an orthagonal varimax rotation) was performed on the staff questionnaire for each of the program components: education; employment; family counseling; and group living. In the employment section, two factors were produced. The first factor was representative of residential employment. These questions regarded the clients' employment skills while working at a job within the residential facility. The second factor represented the community employment of the client. These questions regarded the clients' employment skills while working at a job in the community. The residential employment factor accounted for 44 응 of the total variance. The community employment factor accounted for $43 \%$ of the total variance. In the group living section one factor was produced. This group living factor accounted for $63 \%$ of the total variance.

In the education section three factors were produced. The first factor represented the questions about the client's progress on the Metropolitan Achievement Test. The second factor pertained to questions about the client's 
progress on completing a General Education Diploma. The third factor concerned the questions about the client's success with behavioral management skills. The Metropolitan Achievement Test factor accounted for $26 \%$ of the total variance. The General Education Diploma factor accounted for $25 \%$ of the total variance. The behavioral management factor accounted for $30 \%$ of the total variance. In the family counseling section three factors were produced. The first factor pertained to the questions about the resident's home visit accountability. The second factor had to do with the questions about effective family conflict resolution. The third factor represented the questions concerned with the family's commitment and accountability to counseling assignments and agreements. The first factor, home visit accountability, accounted for $26 \%$ of the total variance. The second factor, family conflict resolution, accounted for $32 \%$ of the total variance. The family assignments and agreements factor accounted for $32 \%$ of the total variance.

A discriminant analysis was performed on collected data to assess whether or not there was any relationship between client choice in treatment and success in the community, and if there was any relationship between behavior change in residence and success in the community. When analyzing the data from the success interview questions, each subject was given an overall success score, 
depending on his answers to the questions during the interview. Those subjects scoring in the top one-third of all the scores produced were put into a "high success" category; the middle one-third scores were labeled as "middle success"; and the bottom one-third scores were the "low success" category. The discriminant analysis produced results indicating that there was a significant relationship between client choice in family counseling and client success in the community, $\underline{F}(2,29)=3.321, \underline{p}<.05$. No significant relationship was found between client choice in education and client success in the community, $\underline{F}(2,29)=1.229$, ns. The results of the discriminant analysis also revealed that there was no significant relationship between client choice in employment and client success in the community, $\underline{F}(2,29)=1.897, \underline{n s}$, and that there was no significant relationship between client choice in group living and client success in the community, $\underline{E}(2,29)=1.171$, ns.

The multivariate test for choice as an overall predictor of client success in the community was not significant, $\underline{F}(8,50)=.963$, ns. As shown in Table I, when using the client's perception of choice as a predictor of client success in the community, only 17 out of the 32 were accurately predicted. 
TABLE I

\section{PREDICTED COMMUNITY SUCCESS BASED ON CLIENT \\ CHOICE VERSUS ACTUAL COMMUNITY SUCCESS \\ AFTER TREATMENT RELEASE}

\section{PREDICTED}

\begin{tabular}{|c|c|c|c|c|}
\hline ACTUAL & $\begin{array}{l}\text { Least } \\
\text { Success }\end{array}$ & $\begin{array}{l}\text { Med i um } \\
\text { Success }\end{array}$ & $\begin{array}{l}\text { Most } \\
\text { Success }\end{array}$ & Total \\
\hline $\begin{array}{l}\text { Least } \\
\text { Success }\end{array}$ & 6 & 3 & 3 & 12 \\
\hline $\begin{array}{l}\text { Medium } \\
\text { Success }\end{array}$ & 4 & 6 & 2 & 12 \\
\hline $\begin{array}{l}\text { Most } \\
\text { Success }\end{array}$ & 1 & 2 & 5 & 8 \\
\hline Total & 11 & 11 & 10 & 32 \\
\hline
\end{tabular}

The discriminant analysis also produced results that supported a significant relationship between the staffs' ratings of client behavior change in residence and client success in the community. As noted previously in the results section, three variables were produced by the factor analysis for the education section. The first variable, Metropolitan Achievement Test scores, was not significantly related to client success in the community, $\underline{E}(2,29)=.316$, ns. The second education variable, General Education Diploma, was found to be significantly related to client success in the community, $\underline{\mathbf{F}}(2,29)=$ $5.074, \underline{p}<.01$. The third variable in the education section, behavioral management skills, did not have a 
significant relationship with client success in the community, $\underline{\mathrm{F}}(2,29)=1.60, \underline{\mathrm{ns}}$.

In the living group section one variable was produced by the factor analysis. The relationship between client behavior change in group living and client success in the community was significant, $\underline{F}(2,29)=9.428$, $\underline{p}<.001$.

The relationship between the two variables in the employment section and client success in the community was also explored using discriminant analysis. The first employment variable, residential employment, was significantly related to client success in the community, $\underline{F}(2,29)=9.652, \underline{p}<.001$. The second employment variable, community employment, was not found to be significantly related to client success in the community, $\underline{E}(2,29)=1.34, \underline{\mathrm{ns}}$.

The multivariate test for the staffs' ratings of client residential behavior change and its overall predictive value of client success in the community was significant, $\underline{E}(12,46)=2.258, \underline{p}<.05$. As shown in Table II, the staffs' ratings of client residential change were accurately predictive of the clients' actual community success in 22 out of the 32 cases. 
TABLE I I

PREDICTED CLIENT COMMUNITY SUCCESS BASED ON STAFF RATINGS OF CLIENT RESIDENTIAL BEHAVIOR CHANGE VERSUS ACTUAL CLIENT COMMUNITY SUCCESS

\section{PRED ICTED}

\begin{tabular}{|c|c|c|c|c|}
\hline ACT UAL & $\begin{array}{l}\text { Least } \\
\text { Success }\end{array}$ & $\begin{array}{l}\text { Medium } \\
\text { Success }\end{array}$ & $\begin{array}{l}\text { Most } \\
\text { Success }\end{array}$ & Total \\
\hline $\begin{array}{l}\text { Least } \\
\text { Success }\end{array}$ & 10 & 1 & 1 & 12 \\
\hline $\begin{array}{l}\text { Medi um } \\
\text { Success }\end{array}$ & 0 & 8 & 4 & 12 \\
\hline $\begin{array}{l}\text { Most } \\
\text { Success }\end{array}$ & 1 & 3 & 4 & 8 \\
\hline Total & 11 & 11 & 10 & 32 \\
\hline
\end{tabular}

The amount of behavior change in family counseling and its relationship with client success in the community were tested separately from education, employment, and group living due to twelve questionnaires that were deleted from the discriminant analysis because of incomplete data. Because of this, only twenty questionnaires could be used in analyzing the relationship between client behavior change in family counseling and client success in the community. There were three separate family counseling variables analyzed. The first variable, home visit accountability, was significantly related to clients' community success, $\underline{F}(2,17)=5.715, \underline{p}<.01$. The second 
variable, effective family conflict resolution, was also found to be significantly related to client success in the community, $\underline{E}(2,17)=3.547$, $\underline{\mathrm{p}}<.05$. The third variable in family counseling, family assignment accountability, did not have a significant relationship with client success in the community, $\underline{F}(2,17)=0.647$, $\underline{\mathrm{ns}}$.

The multivariate test for client behavior change in family counseling as an overall predictor of client success in the community was significant, $\underline{F}(6,28)=3.271$, $\underline{\mathrm{p}}<.01$. As shown in Table III, the staffs' ratings of client behavior change in residential family counseling was accurately predictive of actual client success in the community in 13 out of the 20 cases analyzed. (Asterisk * in Table III indicates cases for which no questionnaire data was available.)

A discriminant analysis was performed on the four previously mentioned variables that showed a significant relationship with clients' success in the community: client choice in family counseling; the second variable in the education section (General Education Diploma); the group living variable; and the first variable in the employment section (residential employment). The multivariate test for these variables showed that there was an overall significant relationship with clients' success in the community, $\underline{F}(8,50)=3.418, \underline{p}<.01$. As presented 
TABLE I I I

PREDICTED CLIENT COMMUNITY SUCCESS BASED ON STAFF RAT INGS OF CLIENT BEHAVIOR CHANGE IN FAMILY COUNSELING VERSUS ACTUAL CLIENT SUCCESS

IN THE COMMUNITY

\section{PREDICTED}

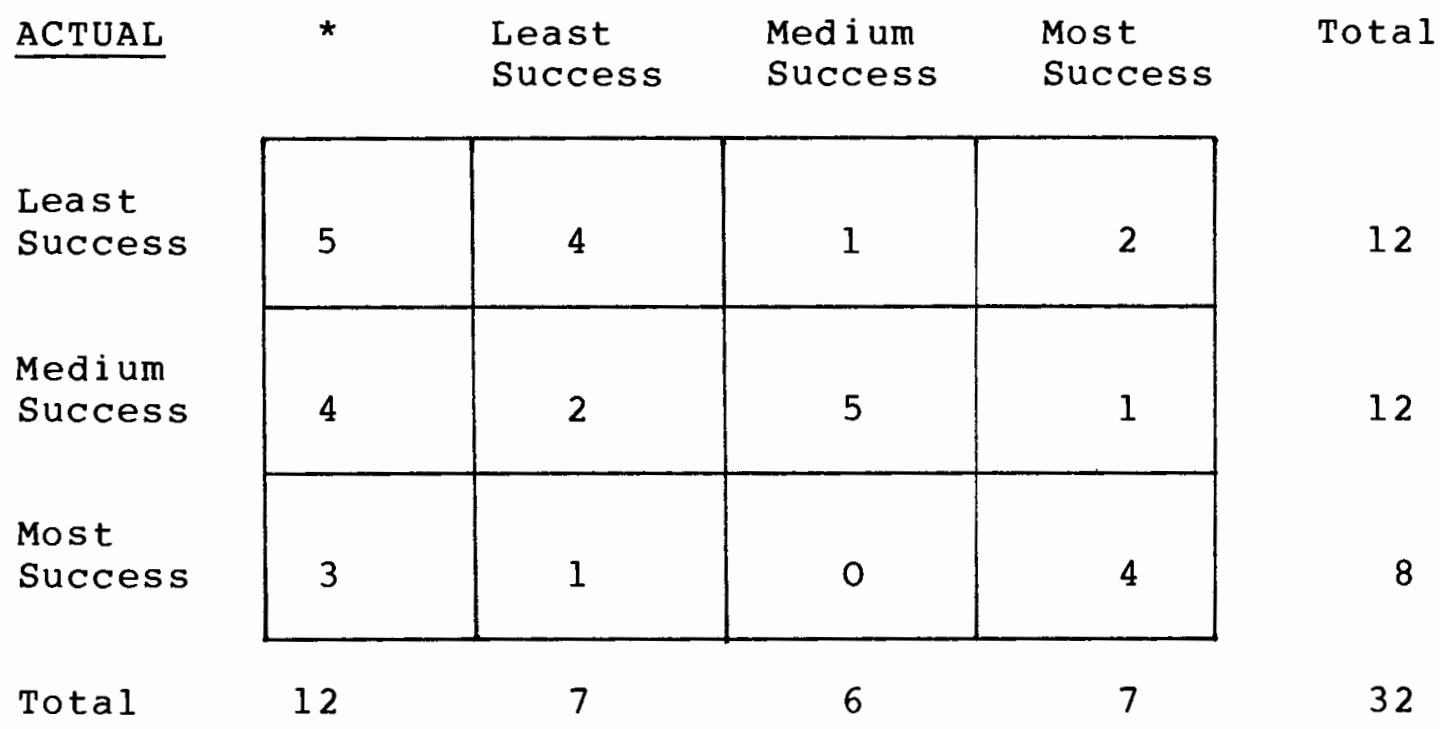

in Table IV, the three significant variables produced from the staffs' ratings of client behavior change in education (General Education Diploma), in group living, and in employment (residential employment), combined with the significant variable produced from the client's perception of choice in family counseling, accurately predicted actual client success in the community in 25 out of the 32 cases analyzed. 
TABLE IV

PREDICTED CLIENT COMMUNITY SUCCESS BASED ON STAFF RATINGS AND CLIENT PERCEPTION OF CHOICE IN

FAMILY COUNSELING VERSUS ACTUAL CLIENT SUCCESS IN THE COMMUNITY

PREDICTED

ACTUAL

Least

Medium

Most

Total

Success

Success

Success

Least

Success

Medi um

Success

Most

Success

\begin{tabular}{|c|c|c|}
\hline 8 & 3 & 1 \\
\hline 0 & 11 & 1 \\
\hline 1 & 1 & 6 \\
\hline
\end{tabular}

12

12

8

Total

9

15

8

32 


\section{CHAPTER V}

\section{DISCUSSION}

The first set of findings regarding client choice is summarized as follows: (a) Overall, client choice in the treatment process was not a significant predictor of client success in the community. (b) Separately, choice in the education, employment, and group living programs was not significantly related to client success in the community. (c) Lastly, client choice in family counseling was a significant predictor of client success in the community. (Since the present findings supported the concept that perception of choice does indeed have an effect on behavior change in the community, it could be reasoned that perception of choice could also have an effect upon behavior change within treatment. An additional analysis, a Pearson correlation, was performed on the present data to explore this possible relationship. See Appendix E for these additional analysis results.)

The second set of findings, regarding clients' positive behavior changes in treatment, are summarized as follows: (a) Overall, clients' positive behavior changes while in residential treatment was a significant factor of client success in the community.

(b) Separately, positive 
behavior changes made within each of the education, employment, group living, and family counseling programs were significantly related to client success in the community.

The hypotheses are supported by the data. It appears that giving clients choices in family counseling can help them to make more lasting and functional behavior changes that generalize successfully to the community. It also appears that clients who make more positive behavior changes while in treatment will continue to engage in these behaviors once they are again living in the community. Bandura's self-efficacy theory provides some understanding of the present $f$ indings. His theory states that modes of psychological treatment, despite their form, affect a person's self-efficacy. The resulting expectations of personal efficacy can influence whether a person will initiate effective coping behaviors and will continue to engage in these behaviors when faced with negative and challenging situations.

In the present study, perception of choice was found to be a significant predictor of clients' success in the community only within the family counseling component of the residential treatment facility. Perhaps perception of choice is an important cognitive element in affecting a person's self-efficacy only while in the presence of significant others such as family members. At the residen- 
tial center family members are not actively involved in the treatment process within the education, employment, and group living program components. It's possible that perception of choice in treatment may only be important to a client when it is within an environment where significant others provide encouragement, validation, and ongoing support of it. Being provided with choices from parents, siblings, a spouse, or other family members, as compared to receiving choices only from staff members, may enhance a client's efficacy expectations. Bandura's theory proposes that a combined sense of personal efficacy and a responsive and supportive environment fosters successful and lasting behavior changes. Those clients who perceived themselves as having had choice in family counseling may have developed strong personal efficacy expectations, thus helping them to develop effective coping behaviors that they continued to use once they were at home in the community.

Another aspect that helps to explain the significance of choice in only the family counseling treatment component is that of client home visits. On regular weekend home visits, the subjects were able to have their choices from the counseling sessions continue to be validated and supported by their families while in their home environments. The subjects, while in family counseling sessions, were given choices about what problem-solving 
skills, communication skills, rules, and consequences would be implemented within the family. While on home visits, the subjects had the opportunities in which to develop personal mastery over these newly-acquired skills; whereas, the subjects did not have these ideal opportunities to be able to develop, practice, and master their skills from the education, employment, and group living components outside of the residential facility. Selfefficacy theory states that performance accomplishments provide the most influential source of efficacy information because it is based on experiences of personal mastery. Since the subjects have had more optimum opportunities to develop personal mastery over family problem-solving skills, it is understandable why there is a significant relationship between client choice in family counseling and client success in the community. These subjects were successful in the community because they were better prepared to deal effectively with obstacles and adverse circumstances.

Even though the present findings do not support perception of choice in the education, employment, and group living components as a significant predictor of client success in the community, it is the belief of this researcher that choice should not be disregarded as an important variable in treatment. Client choice, in conjunction with other treatment variables (e.g.. 
self-competence, motivation, locus of control, and selfesteem), may be significant in enhancing a client's self-efficacy). It would be of benefit to the clinician if future research in this area included exploration of these various factors and their relationship to self-efficacy and client treatment success.

Another area to consider in the present study is that of the success measurement used in the analysis. The measurement of community success in this study was divided into three overall categories: high success; medium success; and low success. Even though the subjects answered specific questions regarding their community status in the areas of education, employment, and living situation, in the analysis each subject received an overall success score and was assigned to one of the three general success outcome measurement categories. The subjects' community successes within the specific areas of employment, education, and living situation were not measured individually. It is possible that the impact of choice in the education, employment, and group living treatment components is not easily measured when using general categories of community success. In future research more specific measures of success should be used in an effort to see if choice is directly related to more specific areas of success in a client's return to the community.

In support of this future research suggestion is a 
study done by Susan Harter. In her study she reported that children's perceived competence had historically been measured by researchers as a unitary construct, and that this was an unreliable form of measurement. She found that children do not feel equally competent in every skill domain; thus she created a perceived competence scale that included the following four subscales: (a) cognitive competence; (b) social competence; (c) physical competence; and (d) general self-worth. Her study supported the concept that children do make distinctions among the different domains in their lives, and that these should be measured separately to assess a child's perceived competence. As mentioned previously, future research in the area of client choice and success should include more specific measurements of client success in the community than the ones used in the present study.

In the findings regarding the staff' ' ratings of client behavior changes, there were specific factors within each of the program components that were significantly predictive of client community success.

Positive accomplishments within the General Education Diploma program at the school were significantly related to community success. One possible reason for this finding is that the clients participating in the General Education Diploma program were of older ages than the clients in the regular school program. These clients were 
between the ages of 16 to 18 years, thus possibly indicating a more mature and serious attitude to make lasting behavior changes in their lives that would be continued within the community. Most of the clients in this treatment facility had experienced several years of school problems and failures. The clients who returned to public school were probably faced with more opportunities to fail than those clients who earned their General Education Diploma and avoided a public school environment.

The two factors produced in the employment component were residential and community employment. Positive behavior changes in residential employment were significantly related to community success. A possible explanation for this finding is that clients usually worked harder on achieving treatment goals in their residential employment than in their community employment. Being eligible for community employment was contingent upon their successful behavior in residential employment. It is possible that since they worked harder on accomplishing successful behavior change goals while in residence, they internalized these behaviors and generalized them more often to the community after they were released.

Positive behavior changes within the group living program were significantly predictive of community success. While in this program, the clients developed effective communication and problem-solving skills. They also 
learned appropriate social skills and how to consistently follow rules and expectations in a structured environment. All of these skills mentioned are valuable tools in leading a successful life. Based on this possible explanation, it seems reasonable that those clients who made many positive behavior changes in this program continued to engage in these successful behaviors after they returned to the community.

In family counseling two factors related significantly to community success. Positive behavior changes in home visit accountability and in effective family conflict resolution were predictive of community success. Clients went home on the weekends to practice their newly-acquired problem-solving skills that they had learned in family counseling sessions. Since the clients were successfully implementing these skills within their home environment instead of in the secure and structured confines of the treatment center, they might have had an easier time continuing these behaviors in the familiar home setting after they left residence.

Bandura's self-efficacy theory may provide some further explanation for the significant relationship between positive behavior change in treatment and community success. Bandura proposes that motivation may be a factor that enhances personal efficacy. The actions of goal setting and the self-evaluative process may be a cognitive 
based source of motivation. Both the anticipated satisfactions of goal accomplishments and the negative evaluations of inadequate performance may provide incentives for client action. At the residential facility, staff members helped the clients to identify treatment goals in each of the four program components. On a regular basis the staff gave the clients verbal feedback, both positive and negative, regarding their progress towards goal attainment. In this respect, staff feedback could have provided incentives for the clients to make positive behavior changes. The more successful the subject was at achieving behavioral goals in treatment, the more likely he developed self-efficacy in these treatment areas, thus providing him with the conviction and expectation that he would continue to implement and maintain these coping skills upon his return to the community.

In conclusion, the concept of self-efficacy is one worth considering within therapeutic environments. The present study provided support for the concept that client choice in treatment may be just one of many factors that enhance a person's self-efficacy. In future studies these variables should be considered when researching client success in treatment. Treatment communities should be developed where clients are given opportunities for goal attainment and personal mastery over behavioral coping skills. In this way clients may be assured the optimal 
conditions to develop self-efficacy, which could then have an impact upon successful implementation of coping skills outside of the treatment environment. 


\section{REFERENCES}

Adams, N. E., Bandura, A., Hardy, A. B., and Howells, G. N. Cognitive processes mediating behavioral change. Journal of Personality and Social Psychology, $19 \overline{77,35}, 125-139$.

Bandura, A. Self-efficacy mechanism in human agency. American Psychologist, $1982, \underline{37}, 122-147$.

Bandura, A. Self-efficacy: Toward a unifying theory of behavioral change. Psychological Review, 1977 , 84, $191-215$.

Bastien, R., and Adelman, H. Noncompulsory versus legally mandated placement, perceived choice, and response to treatment among adolescents. Journal of Consulting and Clinical Psychology, 1984, 52, No. 2, 171-179.

Baum, A., and Singer, J. E. (Eds.). Advances in experimental psychology, (Vol. 2). Hillsdale, NJ: Erlbaum, 1980 .

Brehm, J.W. A theory of psychological reactance. New York: Academic Press, 1968 .

DeCharms, R. Personal causation. New York: Academic Press, $1 \overline{968 .}$

Deci, E. L. The psychology of self determination. Lexington: Lexington Books, 1980 .

Devine, E. A., and Fernald, P. S. Outcome effects of receiving a preferred, randomly assigned, or nonpreferred therapy. Journal of Consulting and Clinical Psychology, 1973, 41, 104-107.

Ersner-Hershfield, S., Abramowitz, S. I ., and Baren, J. Incentive effects of choosing a therapist. Journal of Clinical Psychology, 1979, 35, 404-406.

Gordon, R. M. Effects of volunteering and responsibility on the perceived value and effectiveness of a clinical treatment. Journal of Consulting and Clinical Psychology, 1976, 44, 799-801. 
Harter, S. The perceived competence scale for children. Child Development, 1982, 53, 87-97.

Janzen, W. B., and Love, W. Involving adolescents as active participants in their own treatment plans. Psychological Reports, 1977, 41, 931-934.

Langer, E. J. The illusion of control. Journal of Personality and Social Psychology, $197 \overline{5}, \underline{32}, 311-328$.

Langer, E. J., and Rodin, J. The effects of choice and enhanced personal responsibility for the aged: A field experiment in an institutional setting. Journal of Personality and Social Psychology, 1976 , 34, 191-198.

Lefcourt, H. M. Locus of control: Current trends in theory and research. Hillsdale, NJ: Erlbaum Publishers, 1976 .

Mann, D. National Institute of Juvenile Justice and Delinquency Prevention, 1976 .

Rotter, J. B. Generalized expectancies for internal versus external control of reinforcement. Psychological Monographs, $1966,80,(1$, Whle No. 609).

Statistical Abstract of the United States. United States Department of Commerce, 1985. 
I, (adolescent subject) , agree to participate as a subject in the research project that is related to my previous involvement with (residential tx center), and which will be conducted by Rita McClellan.

I understand that this project involves me answering a questionnaire about the amount of choice I had in treatment, and an interview in which I will answer questions about my experiences since I left the treatment center.

I understand that the possible risks to me associated with this study is the invasion of my privacy and the demand on my time. It has been explained to me that the purpose of the study is to learn if the treatment center can improve its services to clients.

I may not receive any direct benefit from participating in this study, but my participation may help to increase knowledge that will help others in the future.

Rita McClellan has offered to answer any questions I may have about this study and what is expected of me. I have been assured that my participation in this project is confidential and that my answers will not jeopardize any relationship that I may have with the juvenile courts, Children Services Division, or the residential treatment center.

I understand that I am free to withdraw from participating in this study at any time without consequences. I have read and understand the foregoing information.

Signature

Legal Guardian

(if under 18 years of age)

Date 


\section{AUTHORIZATION OF INFORMATION RELEASE}

I, (adolescent subject), give permission for the release of any verbal or written information to Rita McClellan, regarding my residential treatment services while at (residential tx center).

I understand that this information will be used in the research project that is studying the services of residential treatment. It has been explained to me that employees from (residential center) will participate in this study by answering a questionnaire relating to my residential treatment experience.

I understand that all information will be kept confidential and that my identity will remain anonymous. It has been assured that the release of this information will not jeopardize any relationship that I may have with the juvenile courts, Children Services Division, or the residential treatment center. information.

I have read and fully understand the foregoing

Signature

Legal Guardian

(if under 18 years of age)

Date 
APPENDIX B

CHOICE QUESTIONNAIRE

Read the following questions, then circle the number that is the best answer, based on your stay in residential treatment.

\section{EDUCATION}

How much of the time did you have choice in developing and working towards your goals while in the School program?

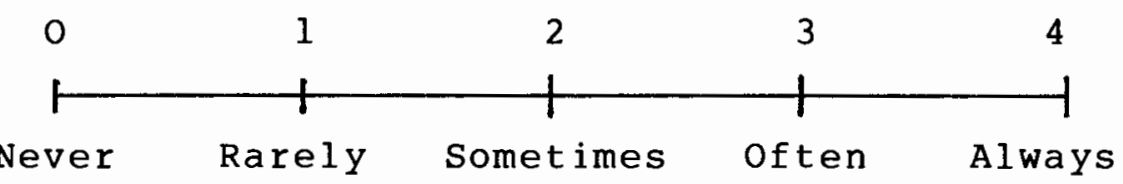

\section{GROUP LIVING}

How much of the time did you have choice in developing and working towards your goals while in the Group Living program?

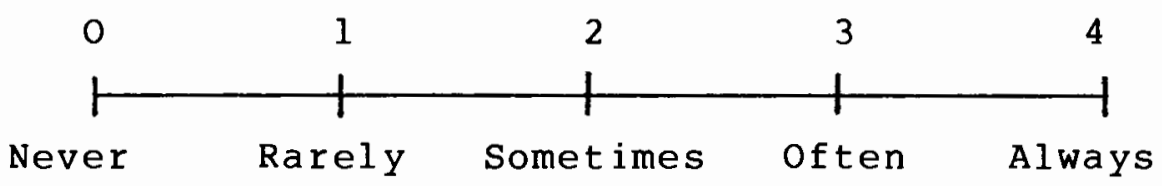

\section{FAMILY COUNSELING}

How much of the time did you have choice in developing and working towards your goals while in Family Counseling?

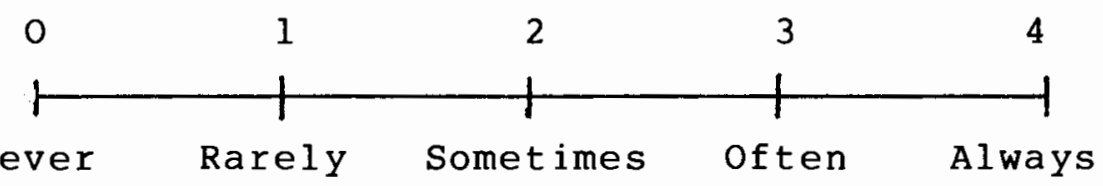




\section{EMPLOYMENT}

How much of the time did you have choice in developing and working towards your goals while in the Employment program?

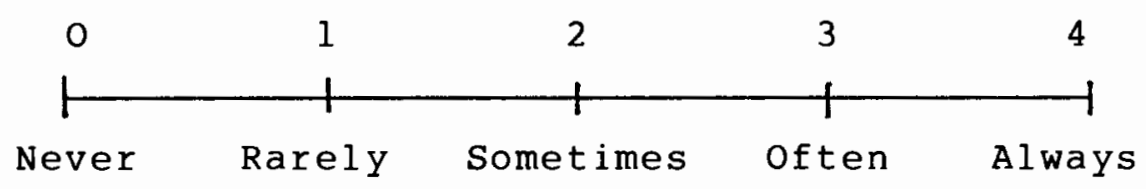


APPENDIX C

SUBJECT INTERVIEW QUESTIONS

1. How many months have you been out of the residential treatment center?

2. How old are you?

3. How many jobs have you had since you left the residential center?

4. How long did you work at each of these jobs?

5. How many of these jobs were you ever fired from?

6. Were you ever in the Navy, Army, Air Force, Marines, or National Guard?

7. Were you honorably discharged?

8. Do you have a high school diploma?

9. Do you have a General Education Diploma?

10. Are you presently in school?

11. Are you presently working on your General Education Diploma?

12. Do you presently have a C.S.D. worker?

13. Do you presently have a juvenile court worker?

14. Do you presently have a parole officer?

15. Since leaving residential treatment, how many times have you been arrested?

16. Since leaving residential treatment, were you ever sentenced to MacLaren?

17. Since leaving residential treatment, was your parole ever revoked so that you had to return to MacLaren? 
18. Have you ever been convicted for a crime as an adult?

19. How many times?

20. Have you ever spent time in the Oregon Correctional Institution, the oregon State Penitentiary, or a Work Release Center? 
APPENDIX D

STAFF QUESTIONNAIRE

\section{EDUCATION}

I. Was the student successful in improving his academic skilis?

How much did the student improve his scores on the Metropolitan Achievement Test?

a. Arithmetic

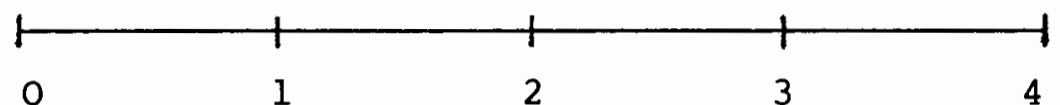

Less than the no. of $2.56 \quad 1$ yr. beyond $\begin{array}{ll}\text { months in residence } & 2.56\end{array}$

b. Reading

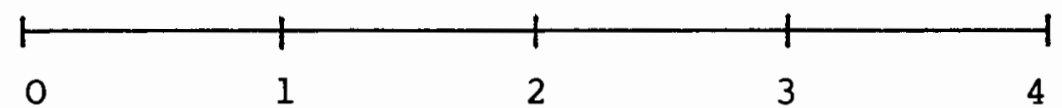

Less than the no. of $1.96 \quad 1$ yr. beyond $\begin{array}{ll}\text { months in residence } & 1.96\end{array}$

c. Language

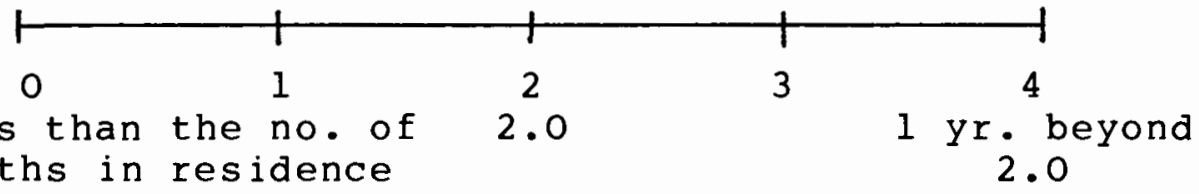

II. How successful was the student in the GED program?

1. Was the student in the GED program?

Yes

No 
2. Did the student complete his GED?

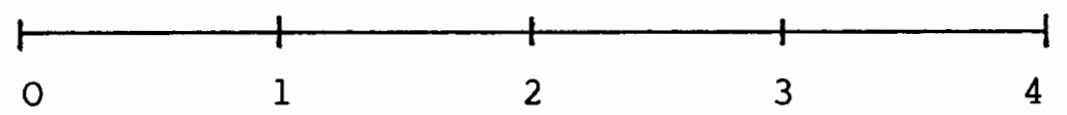

No tests passed

All tests passed

III. Was the student successful with his behavioral management skills?

1. Did the student demonstrate the ability to problem-solve conflicts with peers and staff?

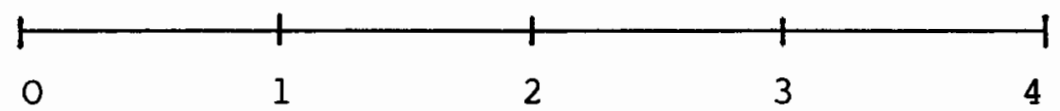

Never Sometimes Always

2. Did the student demonstrate the ability to remain on task?

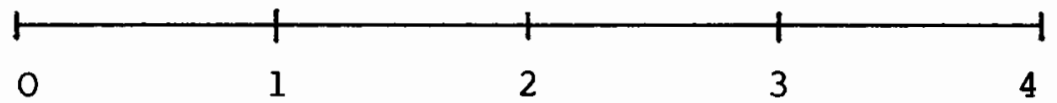

Never Sometimes Always

3. Did the student follow the directions and expectations of the teaching staff?

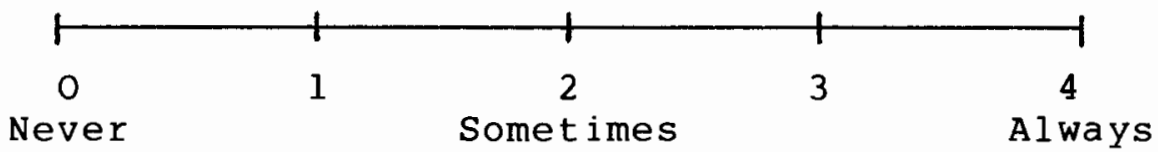

GROUP LIVING

I. How successful was the resident in dealing with his anger?

1. Did the resident express $h$ is feelings of anger with peers and staff in appropriate ways?

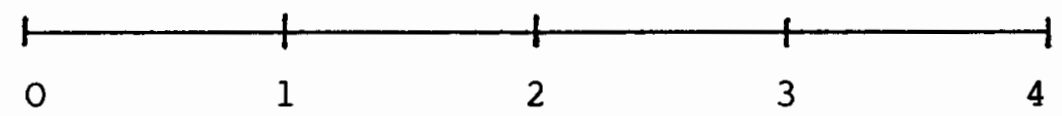

Never Sometimes Always 
2. Did the resident deal with his feelings of anger by using inappropriate methods?

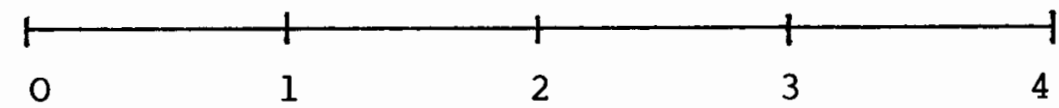

Never Sometimes Always

II. Was the resident successful at making more responsible decisions for himself?

1. Did the resident follow the rules and routines of the residential program?

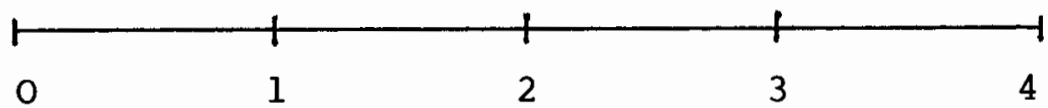

Never Sometimes Always

2. Did the resident confront other peers when they made inappropriate decisions?

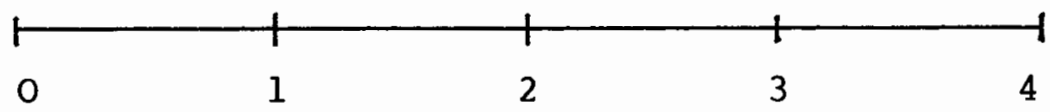

Never Sometimes Always

III. Was the resident successful at living cooperatively with others?

1. Did the resident participate actively and appropriately in group activities?

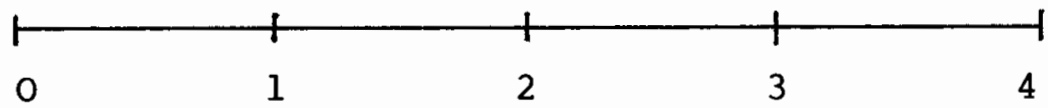

Never Sometimes Always

2. Was the resident helpful, supportive, and respectful of others?

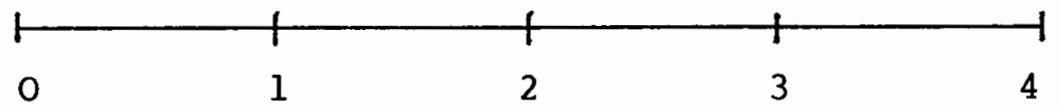

Never Sometimes Always 
I. Was the resident successful in making more responsible decisions for himself?

1. Did the resident follow the rules and expectations of his parents when he was on home visits?

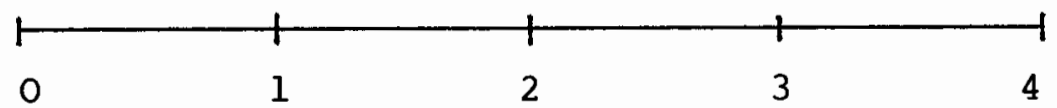

Never

Sometimes

Always

2. Did the resident obey state laws and the rules of his probation when he was on home visits?

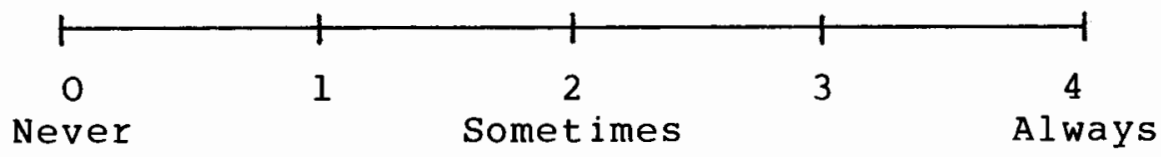

II. Were the family members effective in resolving conflicts?

1. Did the members begin to communicate more effectively due to the family counseling sessions?

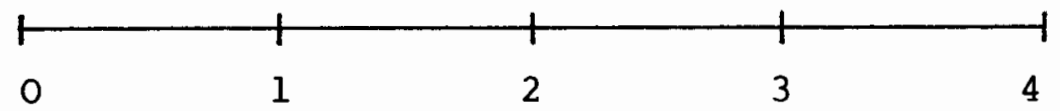

Never Sometimes Always

2. Did the members resolve their conflicts by negotiating and problem-solving?

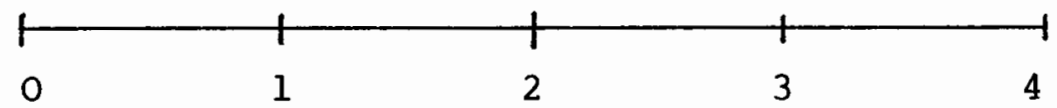

Never Sometimes Always

III. Were the parents successful in practicing effective parenting skills?

1. Did the parents develop reasonable and effective consequences for their child's misbehavior?

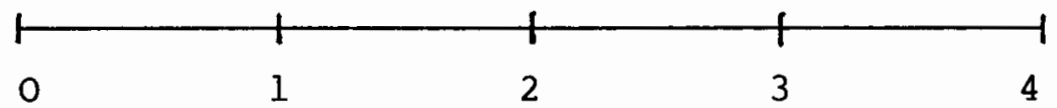

None

Some

Many 
2. Did the parents hold the child accountable by consistently following through with these consequences?

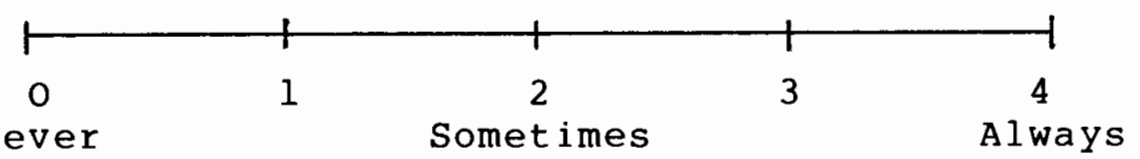

IV. Were the members committed to family counseling?

1. Did the members follow through with the assignments and agreements that were made in family counseling?

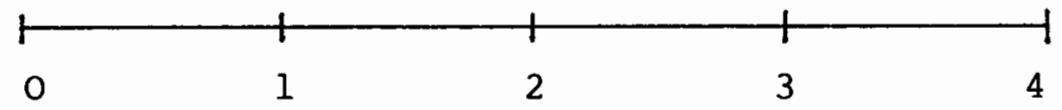

Never

Sometimes

Always

2. Did the nonresidential family members show up consistently and promptly for family counseling sessions?

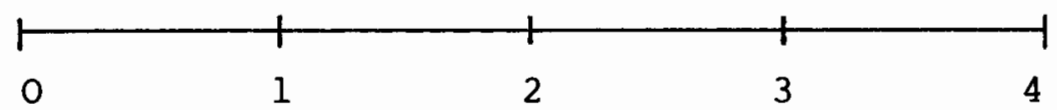

Never Sometimes Always

\section{EMPLOYMENT}

I. Did the resident successfully complete the preemployment Program?

1. Was the resident successful with competency completion?

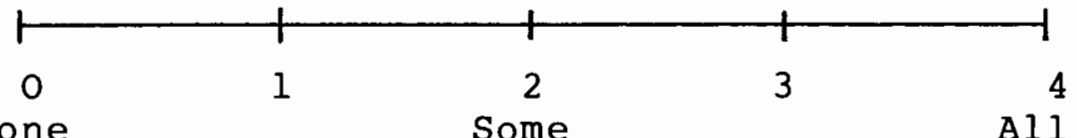

2. Did the resident successfully demonstrate behavior management skills?

a. Did the resident follow the rules and directions?

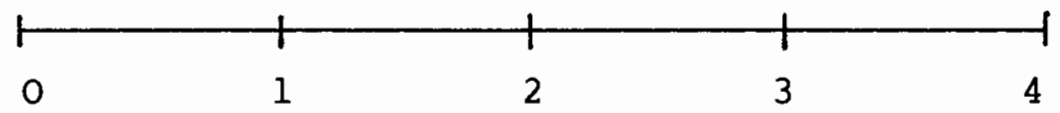

Never Sometimes Always 
b. Did the resident keep busy and remain on task?

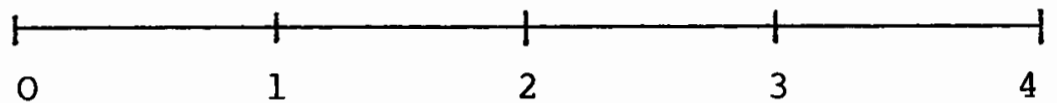

Never

Sometimes

Always

c. Was the resident respectful to peers and staff?

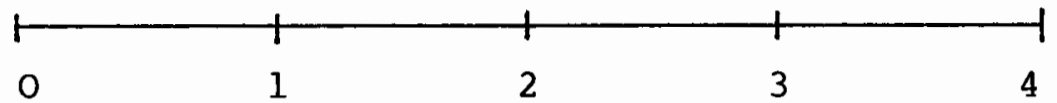

Never

Sometimes

Always

d. Did the resident problem-solve conflicts in appropriate ways?

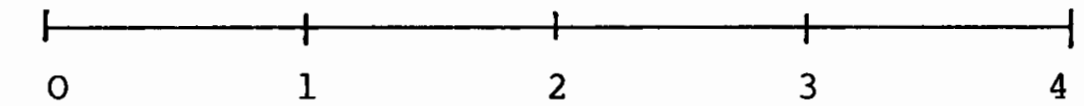

Never

Somet imes

Always

II. Did the resident successfully complete the Work Cluster Program?

1. Did the worker follow the rules and directions?

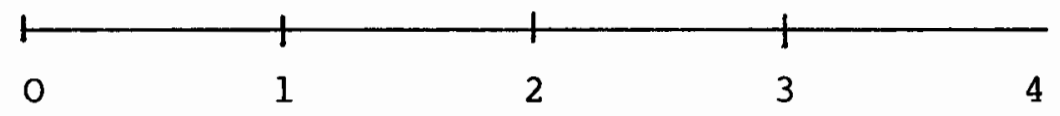
Never
Sometimes
Always

2. Did the worker work independently and show initiative?

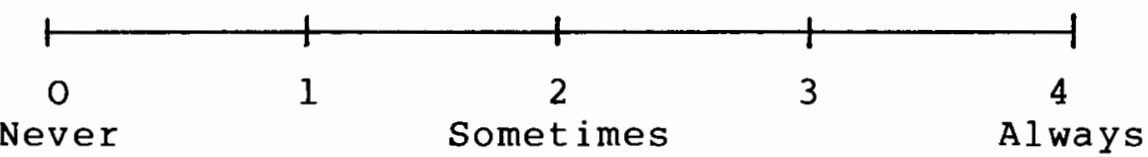

3. Did the worker produce quality work?

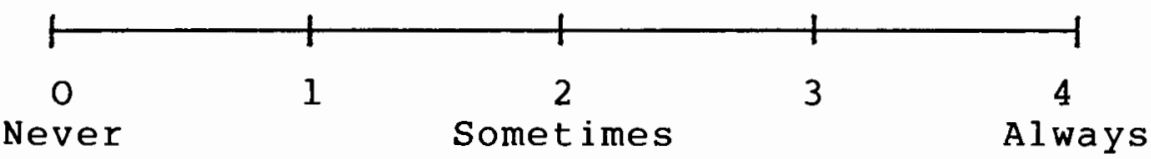


4. Did the worker get along cooperatively with coworkers?

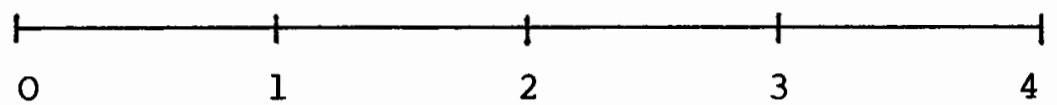

Never Sometimes Always

5. Did the worker get along cooperatively with his supervisor?

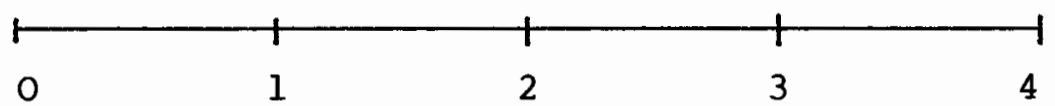

Never Sometimes Always

6. Did the worker successfully complete the program, thus demonstrating that he was eligible for community employment?

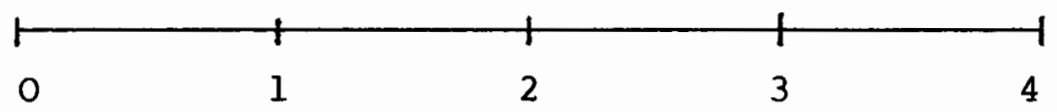

Not eligible Somewhat Eligible Eligible

7. Did the resident become employed in the community?

Yes

No

III. Was the resident successful in his community employment?

1. Did the resident demonstrate punctuality to the job?

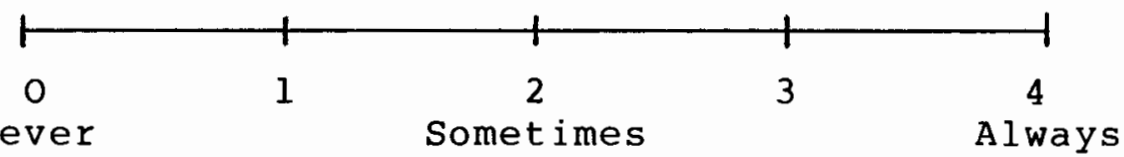

2. Did the resident demonstrate cooperative behavior with his employer?

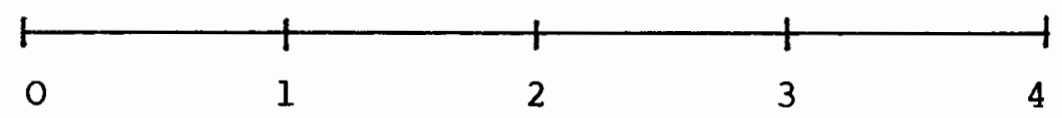

Never Sometimes Always 
3. Did the resident demonstrate cooperative behavior with his coemployees?

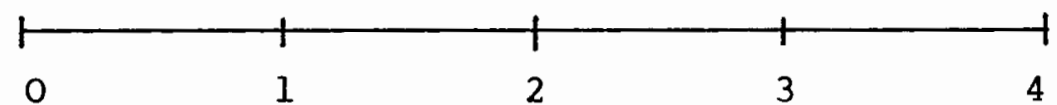

Never Sometimes Always

4. Did the resident follow directions while on the job?

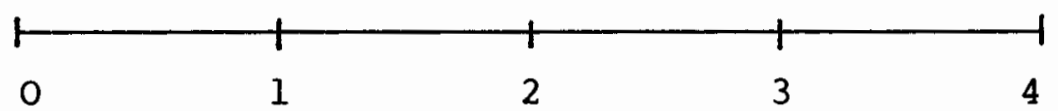

Never Sometimes Always

5. Did the resident keep busy and remain on task while on the job?

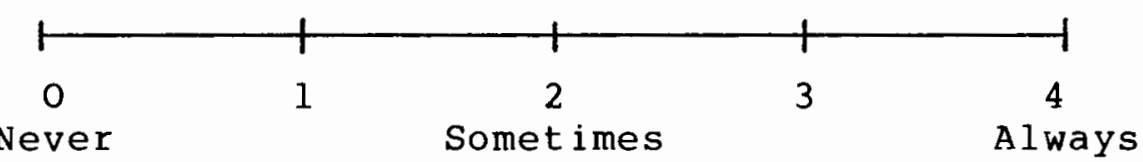

6. Did the resident appropriately notify the employer of any schedule changes?

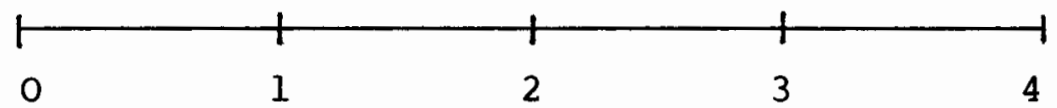

Never Sometimes Always

7. Did the resident appropriately terminate from the job?

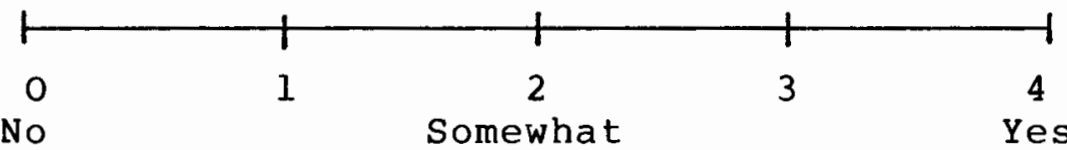




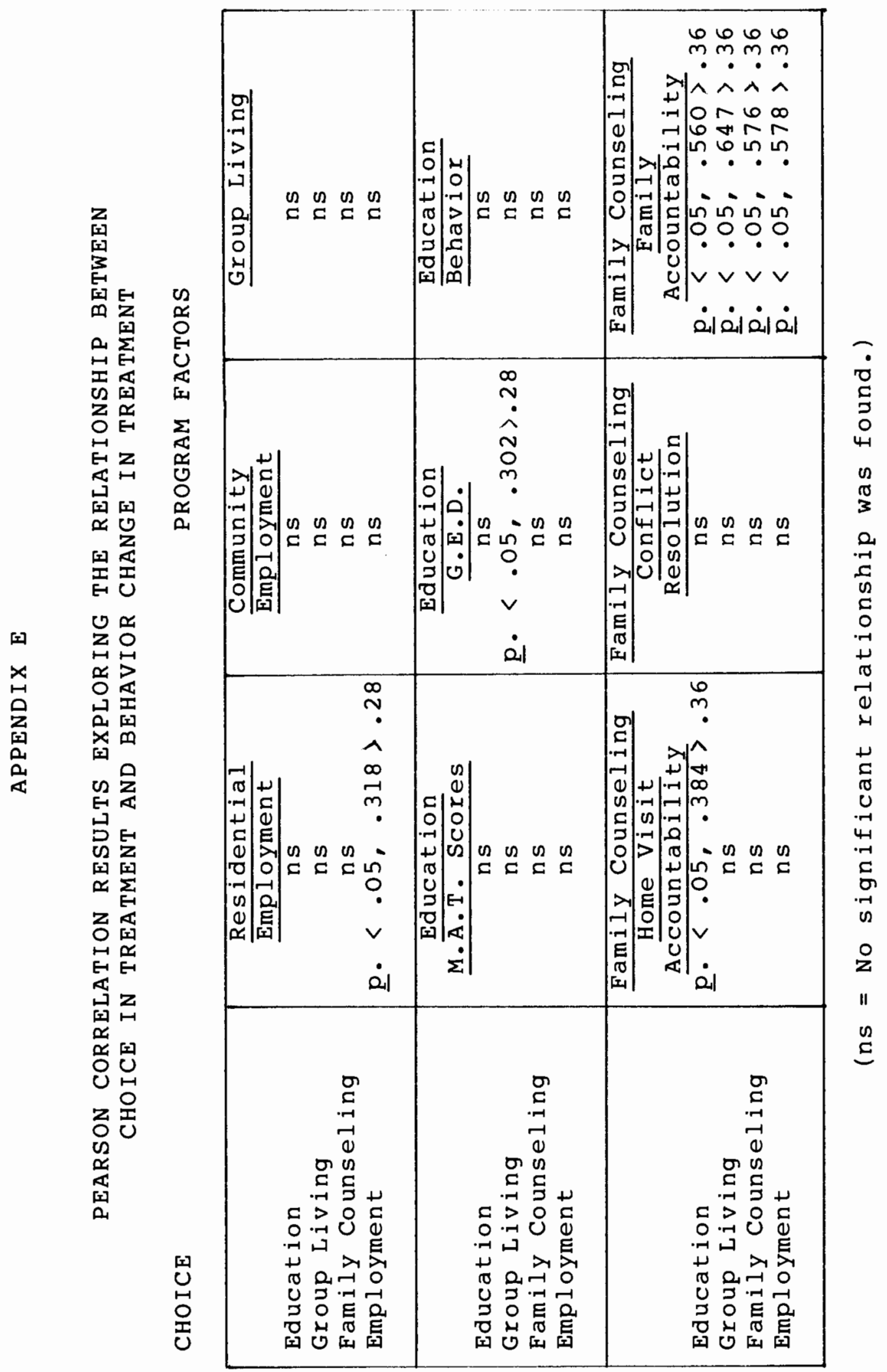

